Journal of Social Sciences 4 (1): 68-74, 2008

ISSN 1549-3652

(C) 2005 Science Publications

\title{
Inciting Striving Speech (i.e., BS) and Imperfect Dialogical Exchanges is exactly what is needed in Higher Education Today
}

\author{
James Carifio and Rocco Perla \\ Graduate School of Education, University of Massachusetts Lowell, \\ One University Avenue, Lowell, MA 01854, Lowell
}

\begin{abstract}
Harry Frankfurt, the American moral philosopher, as well as his many advocates, has initiated a growing movement for eliminating BS from our culture and classrooms. BS is defined as people speaking beyond themselves on some topic that exceed their knowledge of the facts that are relevant to that topic. This article argues that BS and BS-ing (i.e., striving speech and imperfect dialogical exchanges) are key and critical components to both social and intellectual development and that both are something that we want to increase in higher education right now as opposed to the current and past misguided efforts to eliminate them. A variety of current empirical studies and current learning and development theories are reviewed to support this view and recommendations are given to help professors facilitate and encourage striving speech and dialogue among students.
\end{abstract}

Key words: Student engagement, intellectual development, social development, cognitive learning, development theory, argumentation theory, group problem-solving

\section{INTRODUCTION}

Harry Frankfurt's ${ }^{[1]}$ recent book On Bullshit is a formal analysis of a very important and pervasive phenomenon in all human discourse: i.e., Bullshit. Originally published as a journal article 20 years ago in Raritan, the book form published in 2005 by Princeton University Press has received favorable reviews and has been on the bestseller list in several different markets. Frankfurt, an American moral philosopher, attempts to provide a theoretical basis for the study of bullshit, which, in his words, is produced whenever a person's obligations or opportunities to speak about some topic exceed his knowledge of the facts that are relevant to that topic ${ }^{[1]}$. Similar in many ways to Max Black's concept of humbug (quackery, nonsense or pretentious and deceptive misrepresentations that fall short of a lie), Frankfurt clearly takes a negative and pejorative view of what he calls bullshit. Unlike the liar who knows the truth yet chooses to deceive, the bullshitter ignores the truth and is, therefore, a greater enemy of the truth than the liar ${ }^{[1]}$.

After reading Frankfurt's book, we were struck by the following observation: The book and many reviews of the book, seemed to herald this rather playful and provocative commentary as a moral victory of sorts without recognizing its antiquated views of learning, memory, language and thought, as well as the oppressiveness of its main thesis and central argument. Even worse, positive references of the book began to appear in educational philosophy circles and science education without acknowledging any of the instructional and social limitations. Surely Frankfurt's book is a satire, a spoof and a Christmas stocking stuffer-some of our colleagues offered and nothing to be too concerned about really. But this apologist perspective and lack of criticalness of thought that is now so pervasive in education did not sit well with us at all. We wanted to know if other academicians shared, or could even recognize, our concerns. So we quickly composed a review of the book, which was subsequently published in the online journal Education Review $^{[2]}$. The response to our review has been both overwhelming and positive and we feel some sense of satisfaction that educators across the country share our main concern that (BS) is not always bad or subversive to the truth, but often a highly dynamic and necessary matrix for the development of expressive, creative, critical and higher order thinking and representation that gives birth to the truth or/and new truths. Instructionally, the point here is that one can use the developmental and generative aspects of BS to engage students and to facilitate the expression of many different (competing) ideas and views that become

Corresponding Author: James Carifio, Professor, Learning and Instruction, Graduate School of Education, University of Massachusetts-Lowell, One University Avenue, Lowell, MA 01854, Lowell, 
points to reflect on critically and refine, as the student converges toward the shared knowledge of our times in particular areas of study. In philosophical terms, our view of BS values, focuses and relies on the constant interplay between the (generative) context of discovery and the (testable) context of justification, whereas Frankfurt's view of BS completely rejects the context of discovery and its association with the BS construct.

Two Different Kinds of BS (FIBS and RIBS): Simply put, our discontent with Frankfurt's BS construct is that it is too naïve and simplistic to account for the complexities of human thought, language, memory structures, learning and representational systems that have been empirically documented by the cognitive sciences over the past few decades. We certainly recognize that some (and in certain instances many) people appear to flatly ignore the truth and are often compelled to discuss issues they are not knowledgeable about and that these are key diagnostic features of BS according to Frankfurt. And we all do need to be far more reflective, cautious and circumspect when we express ourselves and our views in our fast-paced and fast-changing society, as well as professionally and in high stake situations, because of a pervasive talking heads environment and climate created by our own recent inventions. This aspect and dimension of the phenomenon, however, is not where we disagree with Frankfurt's views or analysis. No, our disagreement is far deeper and more fundamental and important in the long as opposed to the short run in our current instantaneous culture. To just superficially and pejoratively dismiss (as Frankfurt does) all BS-ing behaviors and instances as BS, without addressing the enormous weight of evidence in the cognitive sciences and related fields (including philosophy itself) that has led to a deeper understanding of human behavior, decision-making, thinking and learning, is, in our opinion, somewhat irresponsible intellectually as well as educationally. There are certainly different degrees and types of bullshit that are context mediated, but this finer grained analysis (or perhaps taxonomy) of BS is not suggested or developed in Frankfurt's book.

Further, basic research in language acquisition and development has shown (and continues to show) convincingly that the use of words, concepts and conceptual relations is a highly emotive process that is extremely difficult to develop and that imitation, modeling and talking above oneself or beyond one's comfort zone or experiences is necessary to develop increasing knowledge and skill in a particular area ${ }^{[3,4]}$.
This later point is especially true for highly complex instructional areas such as mathematics, science, philosophy and other highly abstract and technical fields of study.

Perhaps more importantly, bullshit provides a vehicle for cognitive and social engagement and the opportunity to develop more accurate, cogent and informed ideas and views via discussions with more knowledge people ${ }^{[4]}$, however more knowledgeable people are defined. This last point is where Frankfurt's interpretation of bullshit has both oppressive and intimidating undertones and consequences.

There are, therefore, two very different kinds of BS which anchor opposite ends of a continuum. Elsewhere $^{[2,5]}$ we have called the more developmental, generative, expressively striving and creative view of BS outlined above, the Revised Interpretation of BS or the (RIBS) view and model of BS, as opposed to Frankfurt's view of BS which we have called the Frankfurt Interpretation of BS or the (FIBS) view and model. The acronyms and their implicit allusions convey many of the marked differences between these two views we have expressed above and both the dominance and dangers of the FIBS view today, particularly in higher education.

Higher Education Today: Nowhere are the above points seen more clearly than in higher education and higher education classrooms today, where, according to many recent surveys and studies ${ }^{[6,7]} \mathrm{BS}$ and BS-ing has either been reduced to practically zero, or confined to mutual affirmation and confirmations of views, beliefs, doctrines, ideologies and orthodoxies between individuals who talk only to others of their own various subcultures or groups rather than interacting and BS-ing with students and professors who are very different and hold very different views than themselves. Mark Carnes $^{[6]}$, in his recent and very informative article entitled Inciting Speech, reports findings from a large number of national surveys and studies over the last ten years which document how progressively balkanized higher education campuses, students, professors and classrooms have become and have been turned into a bewildering variety and number of enclaves, groups, subgroups, communities, sub-communities and even gangs $^{[8]}$ or police of various kinds ${ }^{[9]}$ to produce what Socrates disparagingly called the culture of reconciliation, in which one of the most notable major effects is to shut off public speech, discourse, discussion and BS-ing between people from all of these different sub-entities. This characterization of the 
current state of affairs and the environment we have created over the past twenty year (as well as the views expressed here) is not a very popular view among professors and higher education administrators currently and is in fact an anathema if not a heresy that is typically reconciled through denial rather than fair and balanced consideration. But that is exactly Carnes' central point.

In short, one of the major, if not the major mechanism for student and faculty growth, development and forging of new views and ideas (i.e., BS-ing with people who push you beyond your comfort zone and encourage you to talk and listen above yourself) has been almost completely shut down and shut off and made almost a structural impossibility, according to Carnes ${ }^{[6]}$ and the voluminous research he sites. We have succeeded in creating an environment on many campuses and elsewhere where speaking on some topic or issue that exceeds one's knowledge of the facts that are relevant to that topic is almost impossible. We have created an environment where speaking BS (and being so impolite as to inflict it on others) is extremely difficult if not impossible to do and where BS-ing and BS sessions in the historical sense of the last 5 millennia have been practically eliminated. Is it really hard to fathom why professors wonder why expressive, critical and higher order thinking skills have dropped ${ }^{[10]}$ for details] and actually bemoan this fact, as well as why students, like faculty, have gone silent in public, as Jonathan Coles ${ }^{[11]}$ recently pointed out to us all in a featured article.

We have succeeded in creating the almost perfect Frankfurt environment where no BS is spoken in the classroom (and most probably outside as well), but the other glaring effect of this seemingly highly prized achievement is that there is no speech and daring professors like Carnes are racking their brains to figure out how to incite speech, which in turn incites intellectual and social development, between all students and all students and their professors, despite the periodic table of current sensitivities that also now must be managed in the process.

This particular set of management skills, moreover, are skills that students need as well as professors to develop, in addition to lessened sensitivities, a focus on and commitment to intellectual and social development and having their views, beliefs and understanding modified and changed in numerous ways which, we all really know, but will not admit in the current climate, is neither a pleasant or neat process or experience most of the time.
Higher Education Classrooms Today: And how bad is this situation really? Carnes summarizes a national study done by the American Historical Association that involved actual classroom observations and evaluations of audio and visual tapes made of those classes that produced what he characterized as awkward revelations. Even the very best professors today in relatively small classes in the liberal arts' courses at the undergraduate level generate very little discussion between students. On the average, students spoke $2.28 \%$ of the time which meant that the professors spoke for 49 minutes of each 50 minute class. Further, the student speech was rarely substantive and confined to factual questions such as will there be a final exam in this course? The vast majority of students were silent in these courses with the best professors who encouraged participation and discussion. These studies, moreover, describe how students today learn to shut up both within class and outside of class, if they have not already learned these behaviors and social skills before getting to the campus as freshman. Further, these studies also describe how intellectual factions, groups and current structural factors and processes such as homogeneous fraternities, dorms and organizations prevent students from having meaningful conversations and BS-ing with those who differ from themselves. Now, if these are the facts for liberal arts courses, what might one predict the facts are for science courses where the need for discussion and BS-ing is as great today as in the liberal arts given the complexity of modern science (and its many nuances) and the impact of science on modern society.

Unfortunately, as Thomas Kuhn documented over 40 years ago, a standard undergraduate education in the sciences does not encourage dialogue or debate at all (and certainly no RIBS-type BS-ing), as the major goal is to inculcate the next generation of scientists into their respective paradigms. Much of the same sort of (decontextualized) scientific education is pervasive today in science courses for non-majors as well, particularly because science faculty often teaches the way in which they were taught. And we all know that there is no BS-ing in Science (of any kind), as well as no room for $\mathrm{BS}$ in science (it is a liberal arts phenomenon) and this lack and discouraging of BS and BS-ing in science classrooms and science teaching just might be part of the reason why scientific misconceptions among students and the general population in this country is such a widespread and pervasive problem. Again, we see yet another glaring possible effect of shutting down and shutting off BS 
and BS-ing in classrooms and particularly RIBS-type BS. We wonder if K-12 students in other counties get to BS more about science and this behavior is a factor in their higher scores (compared to our country) on international science and mathematics achievement tests. So just maybe no RIBS-type BS-ing and attempting to speak beyond one's grasp and knowledge of a topic' or subject matter means less and lower understanding and achievement.

Carnes further summarizes another BS-free environmental phenomenon present currently, which is the right many students and faculty believe and claim they have to express their views without being criticized or challenged even in well mannered ways. This right also corresponded to most students saying that they would not have a discussion (or BS) with someone whose views were very different from their own and that they would only discuss sensitive subjects with those whose views were very similar to their own. Now substitute the words scientific theory for sensitive subjects in the last sentence and you have the current state of many science classrooms in both high school and undergraduate higher education. In addition to vividly describing the balkanization that has occurred and the lack of fraternizing with any enemy whose views are different from your own (and seeing other students and professors as enemies), this right to freedom from criticism and a BS-free Frankfurtian environment is an attempt by its claimants to guarantee their own status quo (and thus freedom from further growth and development), while asserting just the opposite for the enemy, but condemning the enemy also to no growth and development as well (the ultimate intellectual and social stagflation)! Not exactly a good state of affairs in an allegedly changing world, or a view of the other (as opposed to thou) that would make Martin Buber a happy person today if he were alive to observe the current state our of society and classrooms.

To eliminate BS that is respectful, striving and expressive, beyond one's comfort zone and talking above oneself and one's knowledge and understanding is to eliminate intellectual and social engagement both within and outside of the classroom. This kind of BSing and these kind of 'cross-subgroups' BS sessions promote engagement and constructive engagement which in turn promotes and incites social and intellectual growth and development, which RIBS (as opposed to FIBS) BS and BS-ing is all about in the simplest of terms. Further, the most recent National Survey of Student Engagement (NSSE) in higher education not only strongly supports but also elucidates all of these points as well. This survey was based on random samples of 131,256 first year students and 128,727 seniors at 523 participating colleges and universities and is a longitudinal study that has been conducted annually for the past seven years.

Student Engagement Studies: According to the 2006 survey results ${ }^{[7]}$, engagement and interactions between students from differing subgroups has a compensatory effect on growth and development, particularly for minority students and students who enter college with lower levels of achievement. In a word, RIBS-type BSing helps those students who engage in it to grow and develop and the adult students who were so engaged had the highest growth and development of all groups, presumably because their BS-ing skills were more developed and they were more prone to BS-ing. Further, what we tend to forget about RIBS-type BSing and RIBS-type BS sessions is that they are first and foremost socializing and social events that build common bases, values, skills and community between participants. Once this stage happens to some minimal degree, then intellectual views and understandings change and intellectual growth and development begins to occur. The social (and affectively energizing) aspects of RIBS-type BS-ing tend to precede and energize the intellectual aspects and changes, as any successful doctoral student mentor, organizational developer, or coach will tell you.

Specifically, this recent NSSE study found that students who taught and helped other students, collaborated more with peers on projects inside and outside of class, performed community service or volunteer work and had chats with their professors (even if it was by email for distance education students) were more likely to participate in class and be more successful in their courses. It is our view that all of these activities provided energizing opportunities for these students (who are a relatively small minority of current students) to engage in more BS-ing and BS sessions with students, professors and others who were different from themselves and who had views, knowledge and understanding different from themselves. The key it seems is engagement and getting student to engage. In terms of engagement mechanisms and strategies, BS-ing and BS-sessions are one of the simplest, cheapest and most fundamental forms of engagement there are, which prior generations somehow seemed to understand better than we seem to understand currently, with all of our technologies that only seem to get in the way of striving face-to-face 
discourse and generative BS-ing. Again, we want to stress that engagement in the sciences is equally important to engagement in the liberal arts and particularly so for liberal arts students taking science courses and if the results of the NSSE survey are generalizable should lead to higher achievement in science courses by liberal arts students. But another point must also be made here about engagement, BS and BS-ing.

Inciting RIBS Not FIBS or Hate Speech: We want to be clear that RIBS-type BS is not hate speech, it is not putting someone down or creating a hostile environment of various kinds and it is not directed at dominating, or having a view, model, ideology, or theory dominate (a priori and necessarily) without the possibility of logical and rigorous examination and, in many cases, empirical testing. There is already enough of that kind of speech (and ideology) out and about in the world and on higher education campuses currently and this type of speech (and sloganeering) is not critical discourse' and striving for new higher order understandings. This kind of speech is really inappropriate and BS of the kind Frankfurt describes and discusses in detail. We must help students to identify and understand this kind of BS and to distinguish it from RIBS-type BS. RIBS-type BS is very different from this kind of incited speech (often called demagoguery) and is an incited speech of a different kind and a kind that is sorely needed today in education at all levels. In a word, not all BS is bad and a great deal more RIBS-type BS-ing and BS sessions are needed in and outside of classrooms today. RIBStype BS-ing and BS-sessions are the most elementary and fundamental forms, levels and units of engagement and civic engagement, which many great hearts and minds developers (e.g., Socrates and Christ) have engaged in as one of their major modus operandi. Not all BS, therefore, is bad and something to be avoided and eradicated and a lot of the good RIBS-type BS productions are just transitional products and byproducts and drafts on the way to new and higher order understandings and are the essence (i.e., fertilizer) which actually make these new understandings grow and develop. BS and BS-ing, then, is a lot like cholesterol, which means that we want to increase one kind (the good kind) and decrease the other kind (the bad kind). It is our view that the good kind has been squeezed out and just about forgotten in education circles and classrooms and that the price of this squeeze and loss of memory has been and is high. So we have reduced the complex and nuanced views we have expressed above to a slogan (to make everyone more comfortable and happy today in the current environment) of Less FIBS and More RIBS.

Less FIBS and more RIBS is what we need right now in order to incite everyone involved in the educational enterprise to more social, intellectual and educational engagement that will encourage the development of more (interdisciplinary) understanding, new truths and self insights. We need to incite everyone to more than just speech, we must incite everyone to striving speech, speech that is directed at trying to talk above oneself and one's knowledge and grasp to others who are different from oneself and receiving striving speech (feedback) in return that one reflects upon and critically evaluates with an openness to change. Carnes $^{[6]}$ describes many way to incite students (and professors) to striving speech, including role-playing, dramatizations (i.e., theatre in various forms) by students and other forms of discourse that puts both students and professors into the shoes, views, difficulties and thinking of others in a concrete and simulated way. All of the research in the last decade on wait time is also a very powerful and flexible strategy and technique ${ }^{[4]}$. Wait-time is the professor not responding (i.e., not answering a student's question or one the professor poses immediately or pre-maturing, or too quickly intervening between two or more students disagreeing, discussing, or in conflict over a point or issue). Saying nothing and not giving immediate answers lets the silence and non-response exert both discomfort and pressure on students to respond and engage in the process of figuring out and answering questions for themselves, or actively helping each other to do so. Use of collaborative learning models, strategies and projects ${ }^{[12]}$ as well as peer review strategies and techniques are effect methods of increasing RIBS-type BS-ing among students, particularly when the assignments to groups and of reviews are done randomly. Simply providing occasions and opportunities for students to academically socialize with one another without the need or pressure of some highly tangible and prescriptive output or outcome will enhance RIBS-type BS-ing. But particularly having the courage to establish and enforce old fashioned rules of engagement and methods of engagement in classrooms where students are expected and in fact required to express themselves and their thinking and opinions and listen respectively and tolerantly to those of ours and the responses that they receive to their own will increase RIBS-type BSing; namely, less prescription, less professor-talk, more 
student lead discourse and discussion and allowing not knowing-but striving to occur and be acceptable ${ }^{[13]}$.

Perhaps without even realizing it, Frankfurt sends a message that suggests that one should avoid talking bullshit (almost all of the time and because of the risks and potential consequences), or of expressing a developing and non-expert view, concern or opinion. In other words, leave the thinking, discourse and decisionmaking to people who don't talk bullshit (with no definitive or even rough-gauge Turing test of this nonbullshit talk provided by Frankfurt), which is a view that seems to be particularly attractive to many educators and politicians of all persuasions today.

The difficulties with any view that even suggests this type of restriction of intellectual and social engagement are manifest and should be easily identified by most people (and especially by a moral philosopher!). In a world where knowledge (particularly scientific and technical knowledge) is growing exponentially and, at the same time becoming so specialized, it's reasonable to wonder how many people actually exist who don't talk bullshit (or at least a good deal of the time), as well as who is the final arbiter of such decisions.

Frankfurt is correct, however, in assuming bullshit, as he defines it, is ubiquitous, pervasive and growing at an accelerating rate. But one must stop and ask why and ask why in a fairly sophisticated and differentiated way. Not all BS may be bad and something to be radically reduced if not eliminated in all contexts and situations, which is one of our central point's here. Yes, a lot of BS should be scrutinized and we all need to be far more reflective and circumspect when we express ourselves and our views professionally or in high stake situations without doubt. But something as ubiquitous as BS may exist for a reason and perhaps an important and good reason. In our view, bullshit is a matrix for the development of higher-order thinking. The assumption here is that one can go from a (bullshit) matrix that is highly generative (and allows for the thinking and expression of ideas in a less inhibited manner that may not consider the truth or falsity of the expression) to more precise ideas and conceptions that may (or may not be) weeded out by some form of reason, experience, formal testing procedure or logic. Without the development component of bullshit, it would be difficult to understand how scientific ideas, facts, theories and concepts developed from their metaphysical origins to authoritatively accepted and blessed realities.
What Frankfurt fails to recognize is the dynamic nature of the bullshit construct and that bullshit is very often (if not always) an important developmental phenomenon that can be refined over time in a way that leads to more complex (valid) knowledge structures and greater (valid) knowledge capacities. What is missing in Frankfurt's BS construct and also in many psychological, philosophical and epistemological models and theories of knowing is a balanced treatment of the irrational, silly, fanciful, deceptive and emotive nature of thought and behavior, as well as the more logical, formal and scientific ways of thinking and behaving.

Argumentation Theory: In more modern and formal academic terms, the view of BS and BS-ing we are outlining and advocating here is called Argumentation Theory, which is a rapidly emerging area of cognitive psychology and education that is focused on how complex and higher order thinking develops and how thinking, reasoning and belief systems develop and change. Current Argumentation Theory ${ }^{[14]}$, which builds on a lot of dormant seminal research from the 1970's, is (among other things) focused on how research scientists, MD's, executives, political leaders, military commanders and others change their minds, views and theories in the very fuzzy and uncertain worlds they live in where erroneous views and beliefs can have large and serious consequences. Argumentation theory also focuses on how important discourse, dialogue and debate and interdisciplinary (i.e., diverse) discourse communities and processes (and RIBS-type BS-ing) are to these change processes and the process of creating new and better knowledge and understanding.

We are focusing here on the other end of this continuum; namely, the seminal beginnings that start the growth and development of these complex new views, knowledge and understandings and interdisciplinary (and reconciliation) skills of a different kind. We are focused on inciting speech and RIBS-type BS-ing (and are trying to do these things in plain and whimsical speech and language similar to what GellMann and physics did in the 1970's) among students and in classrooms that slowly becomes more interdisciplinary and intellectually diverse in character. We are focusing on inciting and fostering good BS and BS-ing in our classrooms, as well as in our various personal and professional discourse communities and conference sessions. So, one must really ask why 
people seek to speak beyond their grasp and ask if the reasons are always the same and the same in all contexts. And one must ask what are the price and the consequences of just simplistically and unilaterally severely reducing and choking off bullshit in daily discourse, particularly educationally. Maybe a completely bullshit free society (if at all possible) would not be such a complete moral or desirable victory after all. And maybe deception is a far more interesting and important phenomenon than most of us think or realize-especially in the classroom.

\section{REFERENCES}

1. Frankfurt, H., 2005. On Bullshit. Princeton University Press.

2. Perla, R. and J. Carifio, 2006. Review of Harry Frankfurt's book On Bullshit. Education Review, June. (Available online at http://edrev.asu.edu/reviews/rev491.htm)

3. Bruning, R., G. Schraw, M. Norby and R. Ronning, 2001. Cognitive Psychology and Instruction. New York: Prentice-Hall.

4. Schunk, D., 2004. Learning Theories: An Educational Perspective (4th Edn.), New York: Prentice-Hall.

5. Perla, R. and J. Carifio, 2007. Psychological, philosophical and educational criticisms of Frankfurt's BS construct and its instruction implications. Interchange, 38 (2): 119-36.
6. Carnes, M., 2006. Inciting Speech. Organization of American History News letter, 34 (1): 1-10.

7. Washley, P., 2006. Underrepresented students benefit from engagement. Chronicle of Higher Education, 53 (13): A39-42.

8. Gravois, J., 2006. Mob rule. Chronicle of Higher Education, 52 (32): A10-11.

9. Ravitch, D., 2003. The Language Police: How Pressure Groups Restrict What Students Learn. Vintage Books, New York.

10. Innis, R., 2007. Dialogic communication in collaborative problem solving groups. Int. J. Scholarship and Teaching, http://www.georgiasouthern.edu/ijsotl/current.htm

11. Coles, J., 2006. Intellectual diversity in the U.S.: to what end? The Journal of Higher Education, Fall, pp: 13-16.

12. Brookfield, S., 2005. The Power of Critical Theory: Liberating Adult Learning and Teaching. San Francisco: John Willey and Sons, Inc.

13. Frieto, J., 2007. Allowing Not-Knowing in a Dialogic Discussion. Int. J. Scholarship and Teaching, http://www.georgiasouthern.edu/ijsotl/current.htm.

14. Van Eemeren, J. and L. Grootendorst, 2004. A systematic theory of argumentation. The pragmadialected approach. Cambridge: Cambridge University Press. 